\title{
Tumor de células gigantes de la vaina sinovial en la mano
}

\section{Giant cell tumor of the synovial sheath in the hand}

\author{
Diego Eduardo Buendía-Valdez, ${ }^{*}$ Jaime Alejandro Chapus-Reyna, ${ }^{\ddagger}$ \\ Marlene Deyanira Torres-Rivera, ${ }^{\ddagger}$ Mario Alberto Taylor-Martínez ${ }^{\S}$
}

\section{RESUMEN}

El tumor de células gigantes de la vaina sinovial es una lesión benigna con una peculiaridad agresiva. La localización clásica es en el muslo, el tronco y las extremidades, con rara frecuencia en manos. La presentación clínica es diversa; sin embargo, estos pacientes por lo regular muestran aumento de volumen de forma local. Actualmente, aunque existen diversos estudios de imagen de complemento diagnóstico, se requiere el estudio histopatológico para confirmar el diagnóstico. Se presenta el caso de masculino de 40 años que muestra aumento de volumen en falange proximal de dedo anular cara palmar en mano derecha de 2.8 x 1.5 x 1.8 centímetros con limitación de la movilidad.

Palabras clave: Células gigantes, vaina sinovial, nódulo.

Nivel de evidencia: IV

\begin{abstract}
The giant cell tumor of the synovial sheath is a benign lesion with an aggressive peculiarity. The classic location is in the thigh, trunk and extremities, rarely in the hands. The clinical presentation is diverse, however, these patients usually have an increase in volume locally. Currently, although there are several diagnostic complement imaging studies, the histopathological study is required to confirm the diagnosis. We present the case of a 40-year-old male who presents an increase in volume in the proximal phalanx of the ring finger palmar in the right hand of $2.8 \times 1.5 \times 1.8$ centimeters with limited mobility.
\end{abstract}

Keywords: Giant-cell, synovial sheath, nodule.

Level of evidence: IV

\section{INTRODUCCIÓN}

* Ortopedia y Traumatología, Cirugía de Columna, adscrito al Hospital Sedna.

‡ Residente de cuarto año de Traumatología y Ortopedia, Hospital Central Cruz Roja Mexicana.

$\S$ Neurocirugía y Cirugía de Columna, adscrito al Centro Médico ISSEMyM Ecatepec, Adscrito al Centro Neurológico del Centro Médico ABC campus Santa Fe.

Recibido para publicación: 08/01/2020. Aceptado: 02/03/2020.

Correspondencia:

Diego Eduardo Buendía-Valdés

Periférico Sur Núm. 5246, Col. Pedregal de Carrasco, 04700,

Alcaldía Coyoacán, Ciudad de México, México.

Tel: 54241408

E-mail: drbuendia@hotmail.com

Abreviaturas:

TCGVS = Tumor de células gigantes de la vaina sinovial.

USG $=$ Ultrasonido.

$\mathrm{RM}=$ Resonancia magnética.
El tumor de células gigantes de la vaina sinovial (TCGVS) es una tumoración benigna que usualmente se presenta en muslo, tronco y extremidades pélvicas, ${ }^{1,2}$ con una rara frecuencia en manos, representa la segunda tumoración más frecuente de la mano después del ganglión cístico. Puede transformarse en maligno, pues tiene un alto potencial de recurrencia y malignidad. 1

$\mathrm{Su}$ incidencia es de 1/50,000 habitantes, aparece por lo regular dentro de la tercera y quinta década de la vida, ${ }^{3,4}$ afecta con mayor frecuencia al sexo femenino, se manifiesta con un nódulo firme, indoloro, no fluctuante y de crecimiento lento, con localización más frecuente en el dedo índice, seguido del dedo medio, pulgar, anular y meñique, ${ }^{2}$ de predominio en superficie 
An Med (Mex) 2020; 65 (1): 63-66

palmar de los dedos, ${ }^{5}$ involucra comúnmente la articulación interfalángica distal y las falanges proximales. ${ }^{3,6}$

Dentro de los estudios de imagen, a nivel radiográfico se encuentra en 50\%, aumento de volumen a nivel de tejido blando y compresión extrínseca del hueso, produce quistes óseos o lesiones líticas. ${ }^{7,8} \mathrm{En}$ el USG se puede reportar derrame articular, una imagen heterogénea en tejido blando y engrosamiento sinovial. ${ }^{4}$ La tomografía computarizada evidencia múltiples lesiones quísticas subcondrales bien definidas. En la resonancia magnética se observa una imagen hipointensa en T1 y T2. ${ }^{4,9}$

Macroscópicamente se observan nódulos de aspecto lobulado, encapsulados, que pueden presentar bordes infiltrativos, capaces de erosionar el tejido óseo, ${ }^{10}$ su tamaño puede variar de manera significativa entre 0.5 y $5 \mathrm{~cm} .{ }^{11} \mathrm{~A}$ nivel histológico se reporta tejido fibroso y denso, compuesto principalmente de cuatro tipos de células: células sinoviales, células gigantes multinucleadas, células espumosas y células histiocíticas. ${ }^{4,12}$

Entre las opciones terapéuticas, en la actualidad se opta por una resección marginal ${ }^{13}$ con una completa sinovectomía; en caso de involucrar alteración ósea ${ }^{14}$ se recomienda la realización de curetaje, aplicando injerto óseo en caso de ser necesario, en algunos casos se consideran tratamientos coadyuvantes para disminuir la recurrencia. ${ }^{3,14}$

La tasa de recurrencia se encuentra entre 9 y $44 \%$, $2.5 \%$ se manifiesta en un amplio periodo de tres meses a 10 años después de la resección; dentro de los factores asociados con la recurrencia se detecta la presencia de una enfermedad articular preexistente, el involucro óseo, la cercanía con una articulación y la ausencia del gen $\mathrm{nm} 23 ;{ }^{2,13}$ entre los factores en los que no se ha encontrado asociación son la edad, género, tamaño del tumor y la localización palmar o dorsal. ${ }^{13,15,16}$

\section{PRESENTACIÓN DEL CASO}

Masculino de 40 años de edad quien presenta aumento de volumen a nivel de la falange próxima del dedo anular cara palmar de la mano derecha de cuatro años de evolución, el paciente niega antecedente traumático, sin enfermedades crónico-degenerativas conocidas, la tumoración refiere un crecimiento lento, indoloro, pero con una limitación funcional importante para la flexión del dedo por su tamaño y su cercanía a la articulación interfalángica proximal, con características de firmeza, ausencia de dolor y falta de movilidad.

Se solicitó estudio de imagen, una RM (Figura 1), que reveló lesión sólida, de bordes bien definidos, que envuelve casi en su totalidad los tendones flexores del dedo anular a nivel de la falange proximal, la cual mide $2.8 \times 1.5 \times 1.8$ centímetros, con imagen hipointensa y discretamente heterogénea en secuencias de T1 y T2, condicionando una pequeña zona de erosión del hueso cortical en el aspecto volar del extremo distal de la diáfisis proximal del dedo anular por presión extrínseca. Los tendones flexores del dedo anular son de trayecto, grosor e intensidad normal, sin evidencia de tendinosis o ruptura.

Se realizó una resección en bloque de la lesión (Figura 2), con un curetaje de la cortical involucrada en la falange proximal y se logró respetar el tendón flexor del dedo anular, se mandó la muestra a patología, la cual reportó «tumor de células gigantes a expensas de la vaina del tendón flexor», posteriormente se le dio seguimiento al paciente por un periodo de seis meses, en el cual se complementó su tratamiento con rehabilitación física recuperando la funcionali-
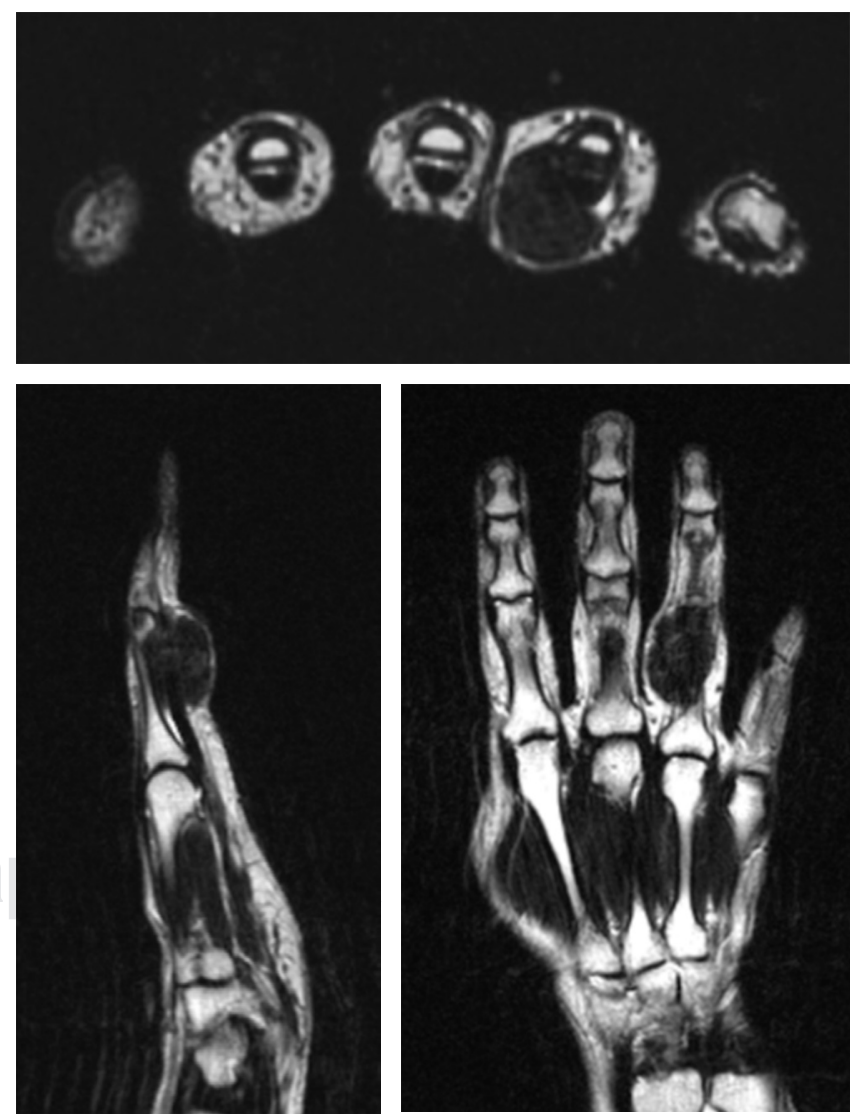

Figura 1: Estudio de resonancia magnética en el que se documenta lesión sólida, de bordes bien definidos, que envuelve casi en su totalidad los tendones flexores del dedo anular a nivel de la falange proximal, la cual mide 2.8 × 1.5 x 1.8 centímetros, cortes axial, sagital y coronal. 

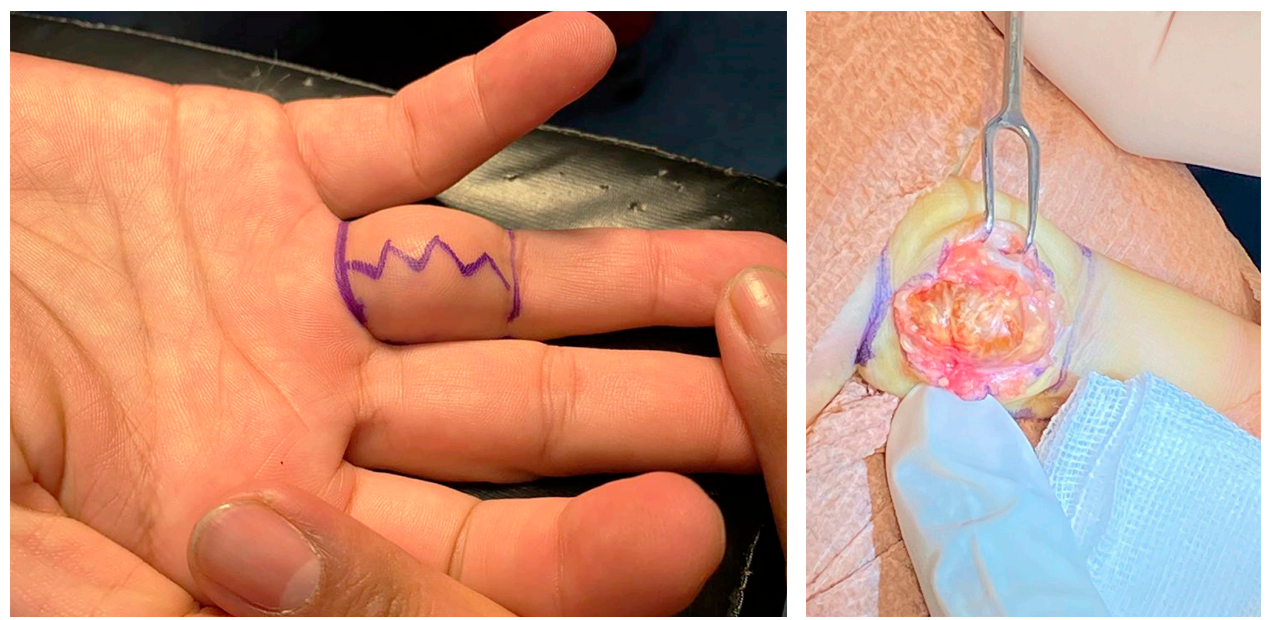

Figura 2:

Muestra de dedo anular con la planeación quirúrgica y la resección de la lesión. dad de la mano al $100 \%$, sin mostrar dolor o datos de recidiva por el momento. Se planificó un seguimiento cada seis meses por los próximos tres años por el alto riesgo de recidiva de la lesión.

\section{DISCUSIÓN}

El paciente presentado en este caso se encuentra dentro de las características detectadas en la revisión bibliográfica: 40 años de edad, ${ }^{2,7}$ afectación del cuarto dedo de la mano, con un cuadro clínico que inició con un aumento de volumen de forma súbita, progresiva e indolora. ${ }^{2,17}$ Se optó por la resonancia magnética como estudio inicial, cuyo reporte reveló las características esperadas. ${ }^{9,16}$ En cuanto al tratamiento, se realizó una resección en bloque tomando en cuenta los márgenes y la erosión en hueso ${ }^{3,14}$ con la finalidad de disminuir de manera significativa el riesgo de recidiva. ${ }^{14,17}$ En la actualidad el paciente se encuentra sin datos de recidiva, complementando su manejo postoperatorio con rehabilitación física, con la cual recuperó al $100 \%$ la movilidad y la fuerza muscular. Se planteó dar seguimiento cada seis meses por un periodo mínimo de tres años con la finalidad de que en caso de presentar reincidencia se realice nuevamente el procedimiento quirúrgico lo más temprano posible y se considere el uso de un tratamiento coadyuvante. ${ }^{14}$

\section{CONCLUSIÓN}

El tumor de células gigantes de la vaina sinovial es relevante por sus características peculiares, se manifiesta en pacientes de edad productiva, puede iniciar con un cuadro inespecífico con sólo un aumento de volumen que puede ser de tamaño va- riable e indoloro, lo que disminuye la posibilidad de alertar al paciente de presentar un problema, el cual a pesar de considerarse de carácter benigno, puede desarrollar una presentación agresiva que forzosamente culminará en un procedimiento quirúrgico, mediante el cual se debe realizar una adecuada resección en bloque por su alta incidencia de recidiva en un periodo que puede variar de tres meses a 10 años.

\section{BIBLIOGRAFÍA}

1. Rao AS, Vigorita VJ. Pigmented villonodular synovitis (giantcell tumor of the tendon sheath and synovial membrane). A review of eighty-one cases. J Bone Joint Surg Am. 1984; 66 (1): 76-94.

2. Fernández-Vázquez JM, Camacho-Galindo J, Romo-Rodríguez R, Cañedo-Patzi AM. Tumor de células gigantes de la vaina sinovial (xantoma). Estudio clínico-patológico de 41 casos. An Med Asoc Med Hosp ABC. 2004; 49 (3): 125-129.

3. Lanzinger WD, Bindra R. Giant cell tumor of the tendon sheath. J Hand Surg Am. 2013; 38 (1): 154-157. Available from: http://dx.doi.org/10.1016/j.jhsa.2012.11.001

4. Garg B, Kotwal PP. Giant cell tumour of the tendon sheath of the hand. J Orthop Surg (Hong Kong). 2011; 19 (2): 218-220.

5. Fotiadis E, Papadopoulos A, Svarnas T, Akritopoulos P, Sachinis NP, Chalidis BE. Giant cell tumour of tendon sheath of the digits. A systematic review. Hand. 2011; 6 (3): 244-249.

6. Erosa-Farah MA, Cortés-Cárdenas SA, López-Íñiguez A. Tumor de células gigantes de la vaina tendinosa en la mano. Rev Esp Méd Quir. 2012; 17 (2): 146-149.

7. Lancigu R, Rabarin F, Jeudy J, Saint-Cast Y, Cesari B, Fouque PA et al. Giant cell tumors of the tendon sheaths in the hand: review of 96 patients with an average follow-up of 12 years. Orthop Traumatol Surg Res. 2013; 99 (4 suppl): S251-S254. Available from: http://dx.doi.org/10.1016/j. otsr.2013.03.008

8. Rodríguez-Acar M, Ramos-Garibay A, Domínguez-Serrato MA, Salcedo-García D. Tumor de células gigantes de la vaina tendinosa. Rev Cent Dermatol Pascua. 2010; 19 (3): 108-111.

9. Briët JP, Becker SJ, Oosterhoff TCh, Ring D. Giant cell tumor of tendon sheath. Arch Bone Jt Surg. 2015; 3 (1): 19-21. 
An Med (Mex) 2020; 65 (1): 63-66

10. Alarcón-Hernández H, Enríquez-Merino J, Novales-Santa Coloma J, Pérez-Cortés S. Tumor de células gigantes de la vaina tendinosa. Reporte de un caso. Rev Cent Dermatol Pascua. 2001; 10 (2): 90-93.

11. Ravi V, Wang WL, Lewis VO. Treatment of tenosynovial giant cell tumor and pigmented villonodular synovitis. Curr Opin Oncol. 2011; 23 (4): 361-366.

12. Reilly KE, Stern PJ, Dale JA. Recurrent giant cell tumors of the tendon sheath. J Hand Surg Am. 1999; 24 (6): 1298-1302.

13. Vogrincic GS, O'Connell JX, Gilks CB. Giant cell tumor of tendon sheath is a polyclonal cellular proliferation. Hum Pathol. 1997; 28 (7): 815-819.
14. Lucas DR. Tenosynovial giant cell tumor: case report and review. Arch Pathol Lab Med. 2012; 136 (8): 901-906.

15. Adams EL, Yoder EM, Kasdan ML. Giant cell tumor of the tendon sheath: experience with 65 cases. Eplasty. 2012; 12: e50.

16. Jelinek JS, Kransdorf MJ, Shmookler BM, Aboulafia AA, Malawer MM. Giant cell tumor of the tendon sheath: MR findings in nine cases. AJR Am J Roentgenol. 1994; 162 (4): 919-922.

17. Díaz-González JM, Domínguez-Cherit J, López-Garza NS. Tumor de células gigantes de la vaina tendinosa: Estudio retrospectivo de siete casos. Dermatologia Cosmet Medica y Quir. 2017; 15 (1): 11-13. 